
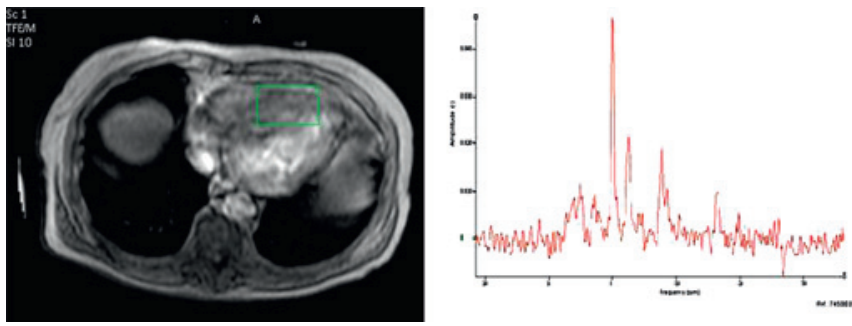

Abstract 95 Figure 1
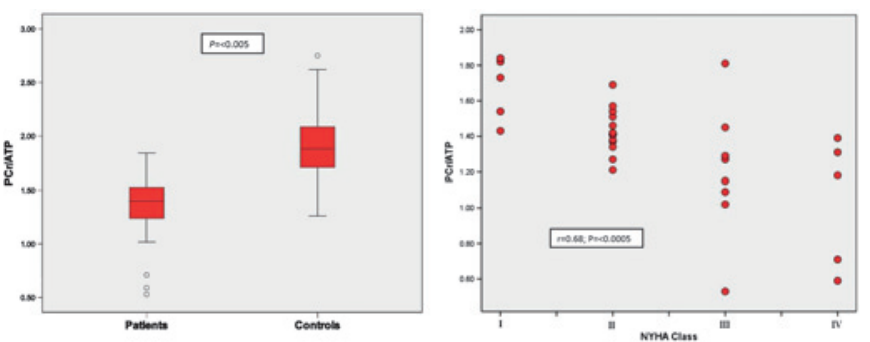

Abstract 95 Figure 2

\section{A TEST TO CONFIRM MAXIMAL OXYGEN UPTAKE IN CHRONIC HEART FAILURE PATIENTS WITHOUT THE NEED FOR SECONDARY CRITERIA}

doi:10.1136/heartjnl-2011-300198.96

T S Bowen, D T Cannon, G Begg, V Baliga, K K Witte, H B Rossiter. University of Leeds, Leeds, UK

Cardiopulmonary exercise testing for peak oxygen uptake $\left(\mathrm{VO}_{2 \text { peak }}\right)$ is widely used to evaluate severity, pathophysiology and prognosis in patients with chronic heart failure (CHF). $\mathrm{AVO}_{2 \text { peak }} \leq 14$ (or 12 with $\beta$-blocker) $\mathrm{ml} / \mathrm{kg} / \mathrm{min}$ is associated with increased mortality and is a key criterion for cardiac transplant listing. A symptom-limited exercise test, however, may elicit a $\mathrm{VO}_{2 \text { peak }}$ lower than the maximum physiological limit $\left(\mathrm{VO}_{2 \mathrm{max}}\right)$; the latter commonly "confirmed" using the secondary criterion of respiratory exchange ratio (RER) $>1.05$. RER, however, is sensitive to the test format. We, therefore, determined if a ramp-incremental (RI) step-exercise (SE) (or RISE) test could determine $\mathrm{VO}_{2 \max }$ in CHF patients without using RER, by satisfying the criterion that two different work rates are terminated at the same $\mathrm{VO}_{2 \text { peak. }}$. Twenty-one male CHF patients (NYHA class I: $\mathrm{n}=3$, II: $\mathrm{n}=16$, and III: $\mathrm{n}=1$ ) initially performed a modified Bruce treadmill test. Patients then completed a symptom-limited RISE95 cycle ergometer test in the format: RI (4-18 W/min; 10 min); 5 -min recovery $(10 \mathrm{~W})$; SE ( $95 \%$ of peak RI work rate). Thirteen of these patients also performed RISE95 tests using slow (RI 3-8 W/ $\mathrm{min}$; $\sim 15 \mathrm{~min}$ ) and fast (RI 10-30 W/min; $\sim 6 \mathrm{~min}$ ) ramp rates. $\mathrm{VO}_{2}$ and RER were measured breath-by-breath by a mass spectrometer and turbine (MSX, NSpire, UK). Peak $\mathrm{VO}_{2}$ and RER were compared within-subjects, between RI and SE, by unpaired t test of the final 12 breaths of exercise. This approach allowed $\mathrm{VO}_{2 \max }$ and its associated $95 \%$ confidence limits to be estimated. $\mathrm{VO}_{2 \text { peak }}$ was similar ( $p>0.05)$ in treadmill and cycle exercise (mean \pm SD: $16.2 \pm 2.7$ vs $15.0 \pm 3.2 \mathrm{ml} / \mathrm{kg} / \mathrm{min}, \mathrm{n}=20$, respectively), despite $R E R$ being greater in cycling $(1.08 \pm 0.12$ vs $1.15 \pm 0.09 ; p<0.05)$. As a group, $\mathrm{VO}_{2 \text { peak }}$ was similar $(\mathrm{p}>0.05)$ between $\mathrm{RI}$ and SE (mean \pm SD: $14.6 \pm 3.2$ vs $14.9 \pm 3.2 \mathrm{ml} / \mathrm{kg} / \mathrm{min}, \mathrm{n}=21$ ). A within-subject comparison, however, revealed that the $\mathrm{VO}_{2 \max }$ criterion was met in 14 of 21 patients (measurement sensitivity range $0.6-3.8 \mathrm{ml} / \mathrm{kg} / \mathrm{min}$ ), despite RER being $>1.05$ in the remaining 7 (1.16 \pm 0.09$)$. There was no effect of ramp rate on $\mathrm{VO}_{2 \text { peak }}(\mathrm{p}>0.05)$, however $\mathrm{RER}$ was greater $(p<0.05)$ in the fast ramp $(1.24 \pm 0.09)$ compared to the slow
(1.12 \pm 0.06$)$. The single-visit RISE95 test incorporating incrementaland step- exercise phases, each to the volitional limit, was well tolerated by CHF patients: The SE phase was contraindicated in only 3 of the 47 tests. The RISE95 detected $\mathrm{VO}_{2 \max }$ in 14 of 21 patients with a sensitivity of $\sim 10 \%$ (ie, similar to healthy subjects), and without the need for secondary criteria or incidence of false-positive. In contrast, the end-exercise RER was sensitive to both modality and ramp rate and provided a false-positive for $\mathrm{VO}_{2 \max }$ attainment in every incidence. Therefore, the RISE95 protocol provides a robust measure of $\mathrm{VO}_{2 \max }$ in CHF patients, to within an individuallydefined CI without dependence on secondary criteria.

\section{INCREASING SKELETAL MUSCLE OXYGENATION BY PRIOR MODERATE-INTENSITY EXERCISE INCREASES AEROBIC ENERGY PROVISION IN CHRONIC HEART FAILURE}

doi:10.1136/heartjnl-2011-300198.97

T S Bowen, D T Cannon, S R Murgatroyd, K K Witte, H B Rossiter. University of Leeds, Leeds, UK

Rapid adaptation of pulmonary oxygen uptake $\left(\mathrm{VO}_{2}\right)$ at exercise onset reduces the reliance on limited anaerobic energy stores and is associated with increased exercise tolerance. These $\mathrm{VO}_{2}$ kinetics, however, are slow in patients with chronic heart failure (CHF). This could be due to limitations in the control of muscle $\mathrm{O}_{2}$ consumption and/or $\mathrm{O}_{2}$ delivery. Recent evidence in CHF of a transient overshoot in microvascular deoxygenation at exercise onset supports the latter. As prior exercise is known to increase muscle blood flow in healthy individuals, we examined whether it could attenuate the fall in microvascular deoxygenation and speed $\mathrm{VO}_{2}$ kinetics on transition to moderate exercise in CHF patients. Thirteen CHF patients (NYHA class I: $n=3$, II: $n=9$, and III: $n=1$ ) performed a ramp test on a cycle ergometer for estimation of lactate threshold (LT) and $\mathrm{VO}_{2 \max }$. Patients subsequently repeated two 6-min moderate-intensity exercise transitions (bout 1, bout 2) from rest to $90 \% \mathrm{LT}$, separated by 6 -min of rest. Measurements included breath-by-breath $\mathrm{VO}_{2}$ using a turbine and mass spectrometer (MSX, NSpire, UK), and tissue oxygenation index (TOI) of the vastus lateralis by spatially resolved near-infrared spectroscopy (NIRO200, Hamamatsu, Japan). The exponential timeconstant $(\tau)$ for TOI and phase II VO2 were estimated using nonlinear least-squares regression. The $\tau \mathrm{VO}_{2} / \tau \mathrm{TOI}$, or "kinetic index", was taken to reflect the relative matching of muscle oxygenation to its instantaneous requirement. LT and $\mathrm{VO}_{2 \max }$ were $9.9 \pm 1.7$ (mean $\pm \mathrm{SD}$ ) and $15.0 \pm 3.2 \mathrm{ml} / \mathrm{kg} / \mathrm{min}$, respectively. Prior exercise increased resting TOI by $10 \pm 3 \%(p<0.05)$, attenuated the transient overshoot in muscle deoxygenation by $\sim 50 \%(p<0.05)$ and slowed the rate of deoxygenation in the transient ( $\tau$ TOI: $10 \pm 1$ vs $21 \pm 13 \mathrm{~s}$; $\mathrm{p}<0.05)$. Both $\tau \mathrm{VO}_{2}(46 \pm 20$ vs $39 \pm 18 \mathrm{~s} ; \mathrm{p}<0.05)$ and the kinetic index $(4.5 \pm 1.8$ vs $2.2 \pm 0.9 ; \mathrm{p}<0.05)$ were reduced following prior exercise. $\tau \mathrm{VO}_{2}$ was well correlated to the kinetic index $\left(\mathrm{R}^{2}=0.92\right)$ in bout 1 . However, although a lower $\tau \mathrm{VO}_{2}$ was typically reflected in a reduced kinetic index in bout $2, \mathrm{VO}_{2}$ kinetics remained slowed in 4 patients. These patients had a higher NYHA class $(2.3 \pm 0.5$ vs $1.6 \pm 0.5 ; \mathrm{p}=0.06)$ and greater initial $\tau \mathrm{VO}_{2}(62 \pm 17$ vs $33 \pm 9 \mathrm{~s} ; \mathrm{p}<0.05)$ than the others. In CHF prior moderate-intensity exercise improved the dynamic matching of muscle oxygenation to its instantaneous requirement and speeded $\mathrm{VO}_{2}$ kinetics in all patients. This suggests that slow $\mathrm{VO}_{2}$ kinetics in $\mathrm{CHF}$ are due, at least in part, to a dynamic limitation in $\mathrm{O}_{2}$ delivery. However, this approach revealed an apparent limitation in the control of muscle $\mathrm{O}_{2}$ consumption in the most severe patients, which was only partly ameliorated by improving $\mathrm{O}_{2}$ delivery. Nevertheless, these findings suggest that an acute intervention to improve muscle oxygenation can increase aerobic energy provision on transition to exercise in CHF patients. 